\title{
A MERCANTILIZAÇÃO DA EDUCAÇÃO PÚBLICA NOS MOLDES DO CAPITAL: AGRONEGÓCIO NA ESCOLA
}

\author{
Érica Nayara Santana do Nascimento ${ }^{1}$ \\ Rosemeire Aparecida de Almeida²
}

RESUMO: O presente texto traz questionamentos acerca da intervenção na educação pública por corporações privadas com intuito de propagar ideologias da agricultura capitalista, impondo uma lógica empresarial à educação pública brasileira. Evidenciamos neste artigo aspectos históricos e contraditórios existentes na execução do Programa "Agrinho", Projeto "Agronegócio na Escola" e pelo grupo "Mães do Agro". Apresentamos algumas estratégias de disputa pela territorialização do capital nas escolas públicas, por meio de projetos educacionais que inserem a instituição pública escolar na ideologia hegemônica da classe dominante, buscando formar sujeitos aptos ao desenvolvimento agrário mercantil no país. Para tanto, procuramos refletir sobre esses elementos a partir de revisão de literatura fundamentada no método do Materialismo Histórico-Dialético. Por fim, foi possível identificar uma diversidade de estratégicas das associações ligadas ao capital que interferem nas ações pedagógicas das escolas públicas via materiais didáticos, palestras, formações de professores, incentivos aos alunos, premiações, utilizadas para propagar a lógica do sistema capitalista no desmonte da educação pública. PALAVRAS-CHAVE: Educação pública; agronegócio; capital; ideologia; Agrinho.

\section{THE COMMODIFICATION OF PUBLIC EDUCATION IN THE MOLD OF CAPITAL: AGRIBUSINESS AT SCHOOL}

ABSTRACT: The present text brings questionings about the intervention in public education by private corporations, in order to propagate the ideologies of capitalist agriculture, imposing a business logic in public policies directed to Brazilian education. In this article, we highlight historical and contradictory aspects existing in the implementation of the "Agrinho" Program, the "Agribusiness at School" Project, and the "Mothers of Agro" group. We present some strategies of dispute for the territorialization of capital in public schools, by means of educational projects that insert the public school institution in the hegemonic ideology of the dominant class, with the intention of forming subjects suitable for the mercantile agrarian development in the country. To do so, we

\footnotetext{
1 Doutoranda em Geografia na Universidade Federal de Mato Grosso do Sul. E-mail: ericanay.geografia@gmail.com

2 Doutora em Geografia, Docente da Graduação e Pós-Graduação em Geografia na Universidade Federal de Mato Grosso do Sul. E-mail: raaalm@gmail.com
} 
tried to reflect on these elements from a literature review based on the HistoricalDialectical Materialism method. Finally, it was possible to identify a diversity of strategies of associations linked to capital that interfere in the pedagogical actions of public schools, directing teaching materials, lectures, teacher training, incentives to students, awards, used to propagate the logic of the capitalist system in the dismantling of public education. KEY WORDS: public education; agribusiness; capital; ideology; Agrinho.

\section{LA MERCANTILIZACIÓN DE LA EDUCACIÓN PÚBLICA EN FUNCIÓN DEL CAPITAL: LA AGROINDUSTRIA EN LA ESCUELA}

RESUMEN: El presente texto trae cuestionamientos sobre la intervención en la educación pública por parte de corporaciones privadas con el fin de propagar ideologías de la agricultura capitalista, imponiendo una lógica empresarial a la educación pública brasileña. En este artículo, destacamos los aspectos históricos y contradictorios existentes en la implementación del Programa "Agrinho", del Proyecto "Agronegocios en la Escuela" y del grupo "Madres del Agro". Presentamos algunas estrategias de disputa por la territorialización del capital en la escuela pública, a través de proyectos educativos que insertan la institución escolar pública en la ideología hegemónica de la clase dominante, con la intención de formar sujetos aptos para el desarrollo agrario mercantil en el país. Para ello, intentamos reflexionar sobre estos elementos a partir de una revisión bibliográfica basada en el método del Materialismo Histórico-Dialéctico. Finalmente, fue posible identificar una diversidad de estrategias de las asociaciones vinculadas al capital que interfieren en las acciones pedagógicas de las escuelas públicas, dirigiendo materiales didácticos, conferencias, formación de profesores, incentivos a los alumnos, premios, utilizadas para propagar la lógica del sistema capitalista en el desmantelamiento de la educación pública.

PALABRAS CLAVE: Educación pública; agroindustria; capital; ideología; Agrinho.

\section{INTRODUÇÃO}

Este texto refere-se a alguns desdobramentos decorrentes da pesquisa de doutorado em Geografia, da Universidade Federal de Mato Grosso do Sul (UFMS), Campus de Três Lagoas (CPTL). Objetiva-se refletir acerca da intervenção de corporações privadas na educação pública via propagação de ideologias da agricultura capitalista, num contexto de disseminação das políticas econômicas neoliberais direcionadas a educação brasileira. Visto que, nos últimos anos, agudizou esse processo de financeirização da educação intermediado pela classe 
NASCIMENTO, E. N. S; ALMEIDA, R. A. A mercantilização da educação pública nos moldes...

dominante que, inclusive, direciona materiais pedagógicos utilizados em sala de aula com a finalidade de promover seus interesses empresariais de classe.

Nessa perspectiva, são desenvolvidos projetos sociais e "programas educacionais" dentro das escolas vinculados a interesses capitalistas de formação de educandos aptos à manutenção do sistema e a reprodução da ideologia da mercadoria, situação que pode enfraquecer as lutas populares de questionamento das contradições capitalistas.

Inicialmente, elaboramos uma breve síntese dos fundamentos ideológicos propagados pelo Serviço Nacional de Aprendizagem Rural (SENAR), atuante em todo o país enquanto instrumento de hegemonia do setor agrário capitalista, com destaque ao seu carro-chefe: o Programa Agrinho.

No sentido de investigar esta atuação, selecionamos o recorte espaçotemporal do Agrinho no estado de Mato Grosso do Sul (MS), desde sua constituição nas escolas públicas estaduais em 2014 até o ano de 2019. A sistematização apresentada é resultado do mapeamento das informações disponibilizadas nas plataformas online do SENAR-MS e do Programa Agrinho-MS.

Posteriormente, evidenciamos algumas estratégias de disputa pela territorialização do capital na educação, a exemplo da incorporação nas escolas públicas de projetos educacionais de interesse privado que representam a classe dos grandes proprietários rurais e empresários, com intuído em formar sujeitos aptos ao desenvolvimento agrário mercantil no país. Neste sentido, Lamosa (2014, p. 101) destaca a Associação Brasileira do Agronegócio (ABAG) que promove desde 2001, o programa educacional "Agronegócio na Escola" no polo regional de Ribeirão Preto-SP, como "um tipo novo de organização da classe dominante, difundido no país a partir dos anos 1990, no processo de reorganização do Estado (adoção do modelo de Estado gerencial) e liberalização da economia". Este cenário marca o fortalecimento da parceria público-privada atuando principalmente na educação básica nas últimas décadas. 
Por fim, como parte deste movimento, destacamos a formação de grupos compostos por mulheres representantes do agronegócio autointituladas como "mães do agro", que usam a mídia para propagação da campanha "De olho no material escolar". Estes grupos de apoio ao agronegócio vêm se organizando no país numa disputa ideológica que tem objetivos comuns, aprofundar a hegemonia do setor capitalista na agricultura via negação das contradições para assim consolidar a acumulação capitalista. Essa movimentação busca incentivar mães e pais responsáveis pelos alunos a fiscalizarem os materiais didáticos utilizados em aula, principalmente no ensino remoto, de modo a comprovar, segundo as "mães do agro", que os professores estariam propagando o conceito do agronegócio brasileiro de forma errônea prejudicando o setor. Ou seja, visam pelo cerceamento da autonomia didática do professor impor sua ideologia de classe.

Procuramos refletir sobre esses elementos a partir de fontes de revisão de literatura fundamentadas nos pressupostos de Lamosa (2014), Lamosa e Loureiro (2014), Leal e Almeida (2005), Camacho (2014), Poulantzas (1974; 2000), Caldart (2008; 2012; 2014), Pereira (2014, 2015), Saviani (1986; 2008), entre outras matrizes teóricas que tratam da temática. Realizamos também uma análise documental para evidenciar os aspectos históricos e contraditórios existentes na execução do programa "Agrinho", projeto "Agronegócio na Escola" e pelo grupo "Mães Agros".

O suporte metodológico deste estudo encontra-se respaldado no Materialismo Histórico-Dialético, a partir do conceito de contradição e ideologia com vistas a realizar uma análise crítica acerca da expansão desta prática empresarial que se subsidia por programas, projetos e grupos pensados para amparar o discurso capitalista de mercado dentro das instituições de educação pública. 
PROGRAMA AGRINHO: UMA PEDAGOGIA DO SETOR AGRÁRIO NA ESCOLA

É importante pensar sobre o panorama histórico e político que define a estrutura fundiária da terra no Brasil, considerando que a classe dominante sempre obteve privilégios do Estado neoliberal, em especial de apropriação da terra e, consequentemente, vem atuando sobre a educação pública por ser "um dos campos de disputa política, mas também pedagógica" (ARROYO, 2014, p. 123). De acordo com o autor, o ajuste neoliberal iniciado no governo Fernando Henrique Cardoso (1994-2002) reforçou as parcerias entre instituições públicas e privadas, qualificou o setor empresarial e deu controle ao patronato rural, que passou a participar da formulação de políticas públicas, no ministério, nas secretariais municipais, estaduais e federais, conselhos, bancadas, entre outras representatividades da classe dominante.

Além da fragilidade nas políticas públicas educacionais, uma crescente e organizada ofensiva do capital vem se posicionando contra as lutas populares, evidenciada por estratégias de disputas que visam a monopolização do capital e o desenvolvimento de projetos voltados à formação de sujeitos aptos ao desenvolvimento agrário mercantil no país. Conforme o MST (2015), a partir da década de 90 uma série de interesses privativos toma o espaço público escolar, numa posição de controle das classes dominantes que articulam projetos de interesse próprio como se fossem da sociedade, auxiliadas pelas Secretarias de Educação. Por conseguinte, a presença do agronegócio nas escolas tem se intensificado, crescendo a interferência nas instituições de ensino público.

Desde então, na tentativa em enfrentar a crise do capital, instaura-se um intenso discurso de cooperação e parcerias de modo a fortalecer o setor mercadológico diante da reestruturação produtiva no território brasileiro, “dessa forma preparando o mercado e o trabalhador, diminuindo assim os riscos ao capital" (PEREIRA, 2015, p. 7). 
NASCIMENTO, E. N. S; ALMEIDA, R. A. A mercantilização da educação pública nos moldes...

Nessa conjuntura, criou-se o Serviço Nacional de Aprendizagem Rural (SENAR), uma entidade vinculada à Confederação da Agricultura e Pecuária do Brasil (CNA), mantida pelo patronato rural nas 27 administrações regionais. Desde sua criação em 23 de dezembro de 1991, pelo Ex-Presidente da República Fernando Collor de Mello, o SENAR vem promovendo cursos de extensão, formações técnicas, capacitações profissionais e projetos voltados ao setor agroindustrial.

O seu carro-chefe é o programa Agrinho, que adentra as instituições escolares de diversos estados brasileiros com pretensão de divulgar entre professores, alunos e toda a comunidade escolar a sua pedagogia política ligada à lógica do capital empresarial. Em 1995, criou-se o Programa Agrinho no Paraná, todavia, de acordo com Rossi, Vargas (2017), objetivou-se desde sua criação atuar de forma abrangente na educação do campo em diversos estados. E há 26 anos promove a idealização do agronegócio a partir de sua atuação nas escolas da rede pública em parcerias com as Secretarias Municipais e Estaduais de Educação.

O Agrinho se constitui na expressão ideológica dominante capitalista. Apresenta o agronegócio como "o" melhor e mais benéfico "modelo de desenvolvimento" agrário que deve ser defendido e aceito por todos já que se trata do mais "moderno", "inclusivo" e "harmônico" sistema de estruturação da agricultura perante a sociedade atual (ROSSI; VARGAS, 2017, p. 219).

O Agrinho ganhou escala na região Centro-Oeste do país, principalmente no estado de Mato Grosso do Sul, em razão da forte parceria entre o SENAR-MS, a Federação da Agricultura e Pecuária de Mato Grosso do Sul (FAMASUL), sindicatos patronais e instituições públicas e privadas. Foi lançado em abril de 2014, e seis meses depois já atendia 31 mil alunos matriculados no Ensino Fundamental de 88 escolas públicas do estado, pertencentes a 8 municípios, sendo estes: Anastácio, Maracaju, Sidrolândia, Ribas do Rio Pardo, Nova Andradina, Terenos, Rochedo e São Gabriel do Oeste. A escolha inicial destes 
NASCIMENTO, E. N. S; ALMEIDA, R. A. A mercantilização da educação pública nos moldes...

municípios para iniciar o programa se deu por questão de logística - considerando a proximidade com a capital, Campo Grande/MS.

Tabela 1 - Programa Agrinho nos municípios Sul-mato-grossenses (2014-2019).

\begin{tabular}{ccc}
\hline Ano & Municípios & $\begin{array}{c}\text { Alunos } \\
\text { participantes }\end{array}$ \\
\hline 2014 & 08 & 31.000 \\
2015 & 20 & 60.000 \\
2016 & 40 & 120.000 \\
2017 & 57 & 184.000 \\
2018 & 66 & 200.000 \\
2019 & $\mathbf{7 2}$ & 160.000
\end{tabular}

Fonte: Dados da plataforma online Agrinho-MS. Adaptado pelas autoras.

A rápida expansão do programa para outros municípios de Mato Grosso do Sul (MS), gerou um aumento no número de apoiadores da iniciativa pública e privada, e de lideranças políticas da bancada ruralista. Nesse contexto, a atuação do Agrinho nas redes de ensino foi se ampliando e no ano de 2019 alcançou 470 escolas da rede pública de ensino, abordando o tema "A Tecnologia do Campo Conectada com a Cidade". No mesmo ano, o programa já atuava em $91 \%$ dos municípios que compõe o estado de Mato Grosso do Sul, pois, dos 79 municípios, 72 foram atendidos pelo Agrinho. (Dados da plataforma online do Programa Agrinho/MS).

Em 2020, o programa Agrinho chegou a sua $7^{a}$ edição com o tema “Práticas agropecuárias que garantem alimentos saudáveis". A novidade ficou por conta da inserção das escolas particulares no programa visando aumentar ainda mais o atendimento do Agrinho em Mato Grosso do Sul. Com esta expansão do programa desenvolvido pelo SENAR, nota-se a hegemonia da territorialização do capital na educação no MS com vistas a manutenção das contradições sociais.

O Agrinho possui ação pedagógica direcionada a professores e alunos do ensino fundamental, e difunde nos espaços escolares seus próprios materiais didáticos que abordam temas relacionados à ética, saúde, meio ambiente, entre 
NASCIMENTO, E. N. S; ALMEIDA, R. A. A mercantilização da educação pública nos moldes...

outras propostas voltadas ao desenvolvimento sustentável e a formação profissional rural para o mercado agroexportador. Para ministrar o conteúdo do programa foram capacitados aproximadamente dez mil professores, instruídos a difundir um discurso de desenvolvimento econômico favorável aos interesses privados do setor agrário capitalista.

Estes materiais agregam conteúdos que não só reforçam a ideologia capitalista da modernidade, como também ocultam o impacto ambiental e humano do uso de agrotóxicos e de produtos transgênicos na agricultura. A região Centro-Oeste possui a maior média anual de uso de agrotóxicos em relação à sua área agrícola, esta realidade não abordada pelo programa Agrinho porque fere seus interesses. Nesta mesma direção, o estado de Mato Grosso do Sul é apontado como o oitavo maior consumidor de agrotóxicos no país (IBGE, 2006), especificamente na parte central e sul do estado, onde se destacam os municípios com maiores porcentagens de estabelecimentos agrícolas que utilizam agrotóxicos, conforme apresentado no mapa elaborado por BOMBARDI (2017). 
NASCIMENTO, E. N. S; ALMEIDA, R. A. A mercantilização da educação pública nos moldes...

Figura 1 - Mapa do Mato Grosso do Sul demonstrando os municípios com maior porcentagem de estabelecimentos que utilizam agrotóxicos no estado.

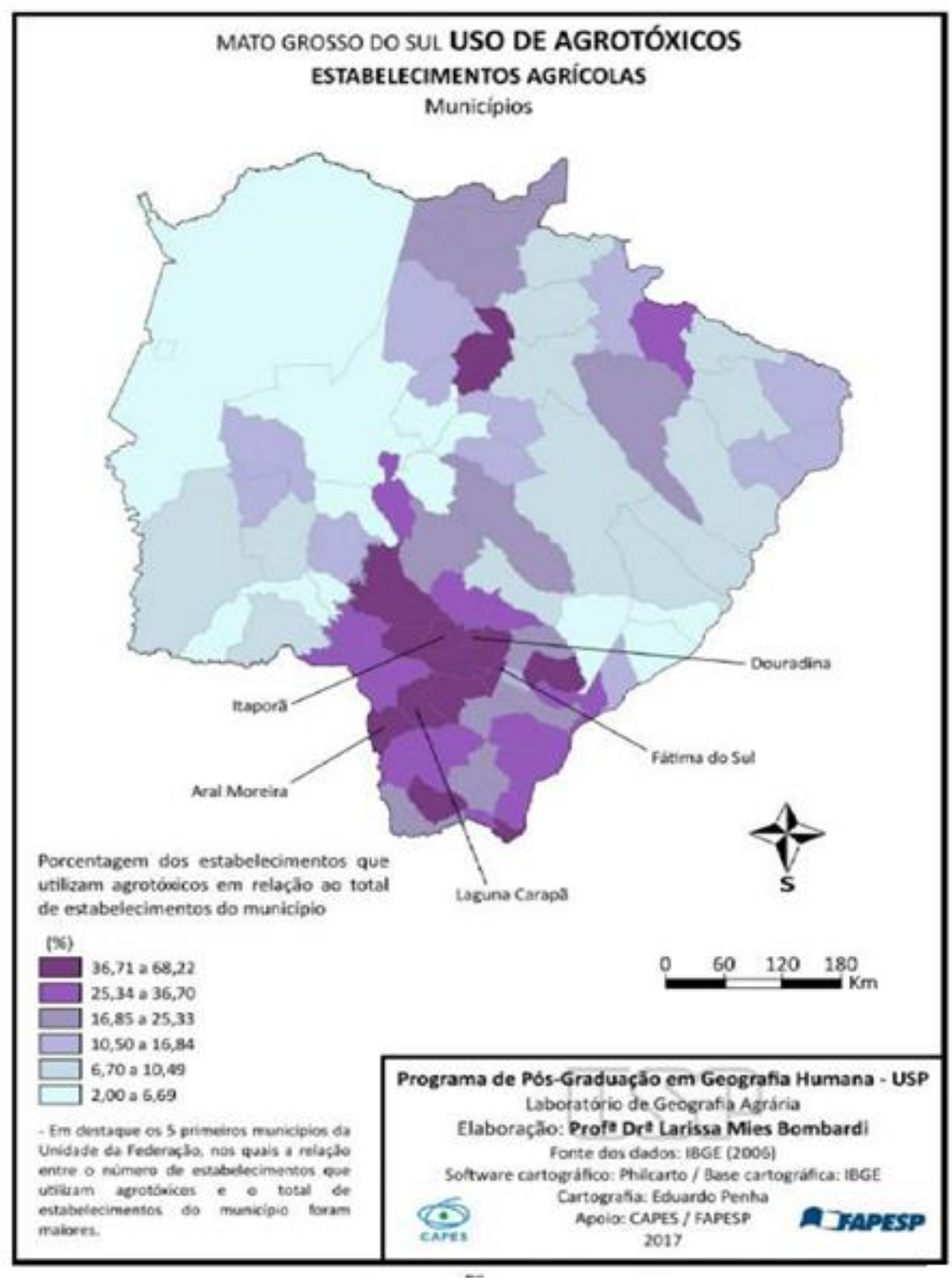

Fonte: BOMBARDI (2017).

Importante destacar a complexidade da questão que está por traz do programa, uma vez que o mercado de agrotóxicos é liderado por empresas multinacionais como a Bayer e Syngenta que, por sua vez, consegue difundir seus interesses empresariais via articulação com ações do Agrinho. Inserido neste contexto neoliberal, a parceria entre empresas privadas e instituições públicas de educação reduzem a formação escolar a um produto a ser comercializado em 
NASCIMENTO, E. N. S; ALMEIDA, R. A. A mercantilização da educação pública nos moldes...

conformidade aos interesses privados da sociedade capitalista, de modo a reproduzir sua hegemonia sustentada pelo setor do agronegócio. As escolas públicas são alvo desses programas e projetos arquitetados, sobretudo, pelos interesses do capital que constantemente mercantiliza a educação, promove os ideários do patronato rural e manipula o trabalho pedagógico dos professores em sala de aula.

[...] muitas empresas adentram na educação pública com programas e projetos que vem imbuído do ideário empresarial. A educação passa a ser um instrumento de divulgação e convencimento das práticas empresariais capitalistas embasados no conceito da sustentabilidade aliada ao empreendedorismo e cidadania (PEREIRA, 2014, p. 05).

O material de formação disseminado nas escolas pelo programa empresarial do Agrinho possui metodologia própria de estudo e verificação da aprendizagem, uma vez que ao final do ciclo organiza um concurso para premiação nas seguintes categorias: redação, desenho, experiências pedagógicas e escola Agrinho. As premiações variam entre as edições de cada regional, podendo ser câmeras fotográficas, impressoras, computadores, TVs, aparelhos de som, Xbox, bicicletas, tabletes, dinheiro ou até um carro zero KM para o professor recrutado na categoria "Experiência Pedagógica".

Para Saviani (1986, p. 29-34), "a escola é o aparelho ideológico dominante, é a ferramenta mais elaborada de reprodução das relações de produção capitalistas". Não discutir essa dimensão política da escola colocada a serviço do capital é deixar os filhos dos trabalhadores expostos a uma educação escolar sem emancipação, capturada pela doutrina e interesses da mercadoria.

PROGRAMA EDUCACIONAL AGRONEGÓCIO NA ESCOLA: UMA INICIATIVA DA ABAG-RP

A presença do agronegócio na educação pública se materializa pela divulgação e desenvolvimento de projetos, programas, palestras, materiais e 
NASCIMENTO, E. N. S; ALMEIDA, R. A. A mercantilização da educação pública nos moldes...

cartilhas, entre outros desdobramentos das corporações capitalistas nas escolas (CALDART, 2014). Exemplo desta organização empresarial que usa a instituição escolar para divulgar a autoimagem do agronegócio brasileiro, é o programa educacional "Agronegócio na Escola", promovido desde 2001 pela Associação Brasileira do Agronegócio (ABAG), no polo regional de Ribeirão Preto, no estado de São Paulo (SP).

Com a finalidade de difundir uma imagem empresarial favorável aos interesses privados do setor, a escola tem sido recrutada e instrumentalizada como espaço de formação mercadológica, conforme explicita Lamosa e Loureiro (2014, p. 535).

A escola, local obrigatório de formação de jovens, neste contexto, passou a servir à divulgação desta imagem. A iniciativa de explorar o espaço escolar como meio de difundir a imagem empresarial foi promovida e materializada durante os últimos dez anos pelas classes dominantes. Desde a data de criação da ABAG, foram organizados diferentes movimentos de entrada de empresários nas escolas públicas brasileiras. Os principais foram: Movimento Brasil Competitivo (MBC), Conselho Empresarial Brasileiro para o Desenvolvimento Sustentável (CEBDS) e Movimento Todos pela Educação. Estes movimentos se caracterizam pela tentativa de unificar princípios dos setores empresariais que atuam no campo educacional.

Outra base de sustentação do programa é disseminar os conceitos fundamentais do agronegócio para as salas de aula. Esta "conceituação" é difundida pedagogicamente envolvendo professores incentivados a reproduzir na prática docente um discurso de ordem capitalista. Para tanto, precisam utilizar os materiais de orientação elaborados pelo próprio programa que, por sua vez, ressaltam temas e slogans direcionados a mostrar aos alunos das escolas públicas a importância do agronegócio para a economia do país, como a cartilha oficial da ABAG-RP na edição 2012, intitulada: "Agronegócio: sua vida depende dele". 
Figura 2 - Cartilha apoio "Agronegócio: Sua vida depende dele"

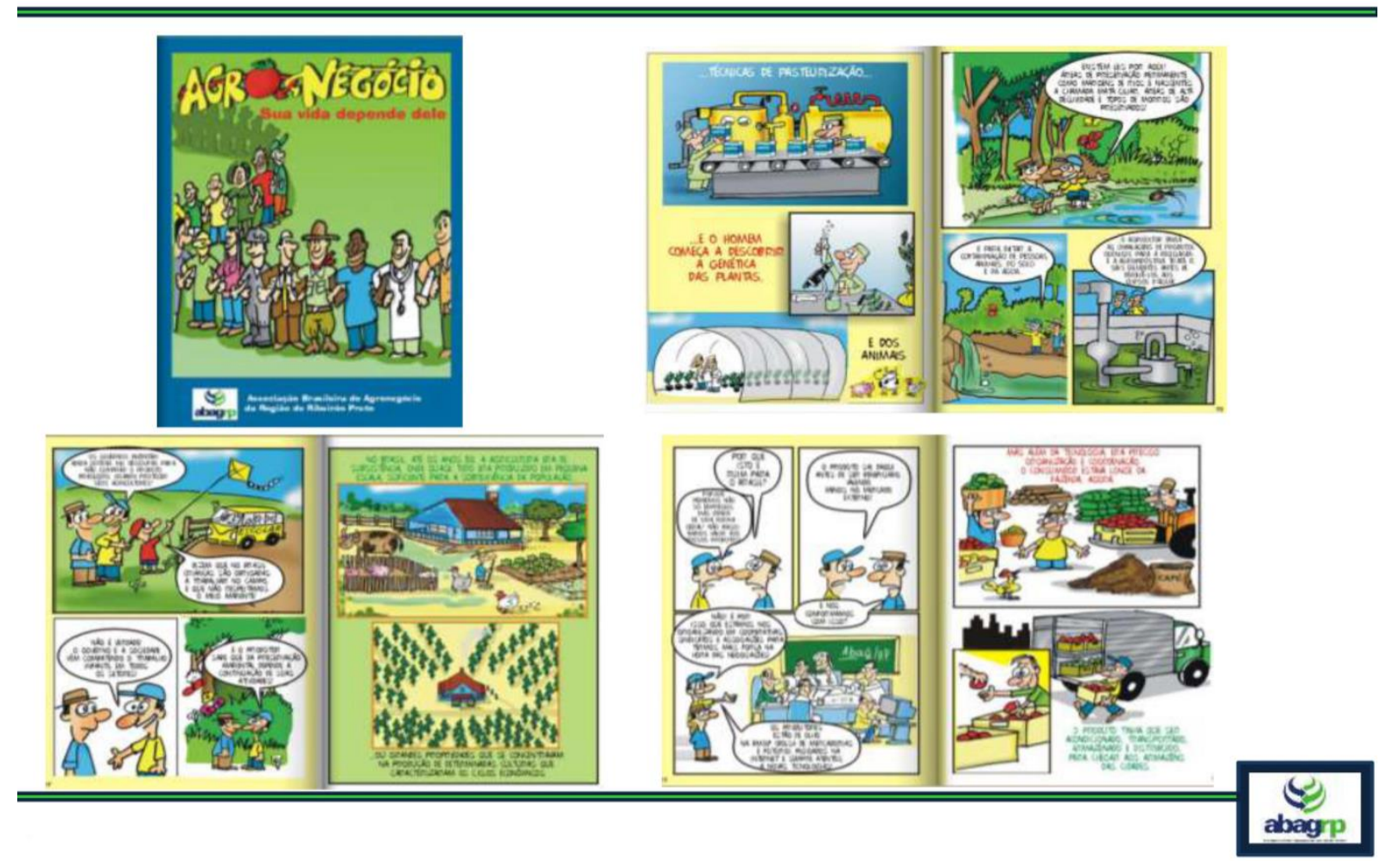

Fonte: https://www.abagrp.org.br/metodologia

Esse slogan apresentado na cartilha deixa evidente o que Duarte (2005, p. 06) nos aponta, ao afirmar que "as classes dominantes precisam manter parte da população presa à ideia de que não existe outro caminho para a humanidade a não ser a total adaptação às regras impostas pelo mercado mundializado".

Além da capacitação formativa da ABAG-RP, também ocorrem concursos nas categorias de desenhos, elaborações de frases, redações e projetos, em que são premiados alunos, professores e instituições escolares. Ou seja, o conjunto da comunidade escolar é envolvido como ideólogos do programa Agronegócio na Escola, a partir de uma metodologia própria pautada na abordagem da pedagogia empresarial ligada ao cenário produtivo do país. De modo geral, tal modelo pedagógico dá sustentação ideológica a esse misto de neoliberalismo e pósmodernismo que caracterizam as políticas educacionais (SAVIANI, 2008). 
NASCIMENTO, E. N. S; ALMEIDA, R. A. A mercantilização da educação pública nos moldes...

Trata-se na realidade do apagamento e desmonte da agricultura camponesa para fortalecer a agricultura capitalista, usando escolas, alunos e professores como instrumentos de propagação ideológica em direção a mercantilização da educação brasileira, em que o ensino é pautado por interesses de empresas privadas em articulação com segmentos produtivos, sobretudo do agronegócio no Brasil. Em seu caráter burguês, “o Estado tem uma relação de favorecimento com as classes dominantes em detrimento da luta pela melhoria de vida dos pobres" (LEAL; ALMEIDA, 2005, p. 05).

Neste cenário de vínculo entre a instituição privada e a instituição pública, nota-se o quanto a educação tem se tornado instrumento de difusão ideológica de interesses privados como se fossem públicos. E nessa lógica, o Estado dá suporte ao controle capitalista realizado pelas corporações, a fim de atender os interesses econômicos e políticos voltados ao rentismo, como historicamente aconteceu com a concentração de terra no país e, agora, em andamento no contexto da educação brasileira, visto que, “a lógica antagônica é clara e, portanto, não há possibilidades de se construir mudanças em 'parcerias' com o capital". (CAMACHO, 2014, p. 400).

Consolidando esse processo mercadológico pautado sobre a ótica capitalista, a ABAG-RP com seu projeto trunfo "Agronegócio na Escola" há 20 anos usa o espaço escolar e seus sujeitos para conduzir uma visão ideológica de modernidade e harmonia da agricultura capitalista, conforme seus interesses privativos.

\section{MÃES DO AGRO NO COMPASSO DA BANCADA RURALISTA}

A conjuntura política do país evidencia que os interesses dos capitalistas do campo são priorizados em detrimento da classe camponesa, está última responsável em alimentar o Brasil. Este paradoxo tem sido denunciado e enfrentado pela Educação do/no Campo em disputa com a educação empresarial 
NASCIMENTO, E. N. S; ALMEIDA, R. A. A mercantilização da educação pública nos moldes...

que, como visto, busca a reprodução do capital que tanto se fortaleceu no bojo da contrarreforma neoliberal. As políticas públicas firmadas em parceria com o mercado se fortaleceram em tão elevado grau, que o agronegócio passou a ditar rumos para a educação brasileira via promoção de campanhas contendo poder discursivo e persuasivo em função do interesse privado, perseguição a professores, interferência no currículo e no material didático de escolas públicas. E desse modo, "o capital utiliza-se da educação como um dos meios para consolidar sua hegemonia" (PEREIRA, 2015, p. 27).

Neste contexto, é que se cria um grupo de mulheres representantes do agronegócio autointituladas como "mães do agro" que articula na mídia a propagação da campanha "De olho no material escolar". Essa movimentação visa incentivar mães e pais responsáveis pelos alunos, a fiscalizar os materiais didáticos utilizados nas aulas, principalmente no ensino remoto, com intuito de comprovar, segundo as "mães do agro", que os professores estão trabalhando de forma errônea e prejudicial a conceituação do agronegócio brasileiro. Esse registro é orientado a ser feito por meio de fotos e vídeos que evidenciem a expressão conceitual de uma "imagem negativa e preconceituosa do agronegócio sem embasamento científico", conforme dizem os parlamentares da Bancada Ruralista - representantes do eixo político que apoiam os interesses do agronegócio no Congresso Nacional.

Em todas as regiões brasileiras encontra-se uma série de movimentos organizados por mulheres defensoras do agronegócio no país, os grupos são compostos por esposas de grandes latifundiários, gestoras de propriedades rurais, agrônomas, técnicas agrícolas, entre outras colaboradoras que se reúnem para questionar o que chamam de fake News do agro, propagar informações sobre os defensivos agrícolas de forma positiva, conforme postado no site Mulheres Do Agronegócio no ícone "História do início do Movimento Agroligadas". Cujo propósito, é explicitamente descrito por Geni Schenkel, fundadora e 
NASCIMENTO, E. N. S; ALMEIDA, R. A. A mercantilização da educação pública nos moldes...

presidente do movimento Agroligadas no estado de Mato Grosso, esposa de Alexandre Pedro Schenkel que exerceu a função de presidente da Associação Mato-Grossense dos Produtores de Algodão (AMPA) até 2016. Atualmente, Schenkel faz parte da diretoria para o Triênio 2020/2022.

Conseguimos definir nosso propósito, nossa missão, redesenhamos nossa logomarca, definimos governança, produzimos produtos, aumentamos nossa rede de contatos no agro e realizamos duas ações grandiosas no ano de 2019. O Primeiro dia de Campo Agroligadas - Ligando o Campo a Cidade, onde atendemos 106 alunos do nono ano do ensino fundamental e professores de três escolas. O Workshop Agroligadas - Capacitar para Transformar, com a participação de 150 mulheres do estado que teve o objetivo de apresentar a estruturação do movimento e melhorar a nossa comunicação. Ambos eventos de sucesso total, conseguimos apoio de todas as instituições do agro do estado e de algumas multinacionais e por onde passamos no ano de 2019 fomos muito bem recebidas e sentíamos a todo instante que todos ansiavam por isso. O ano de 2020 começou com 400 mulheres cadastradas no movimento agroligadas e foi planejado com algumas idealizações e muitas ações, mas diante a essa pandemia tivemos que reestruturar tudo. Organizaríamos alguns eventos presenciais e estaríamos concretizando o sonho de implantar núcleos locais em algumas cidades do estado e fora dele também. Hoje temos mais de 500 agroligadas cadastradas, todas com ligação direta ou indireta com o agro, unidas a nosso propósito de transformar e unir a sociedade rural e urbana em uma só. (Mulheres do Agronegócio. http://missaomulheresdoagro.com.br/historia-agroligadas/. Acesso em 12/07/2021).

Condizente com a ideologia do grupo Agroligadas, Tereza Cristina Correa da Costa Dias, ministra da Agricultura, Pecuária e Abastecimento (MAPA), no atual Governo de Jair Bolsonaro (2019-2022), ressalta que os conteúdos existentes nos livros didáticos transmitem informações atrasadas e incorretas sobre o agronegócio. Em consequência, colocam o setor agroindustrial como altamente responsável pelo trabalho escravo no país, formando alunos com conteúdo incoerente com a realidade do agronegócio. 
Como parte deste movimento voltada à criação de redes e organizações que não só fortalecem a capacitação feminina no desenvolvimento da agricultura capitalista, mas também o seu reverso que é o apagamento da agricultura camponesa, Clélia Steinmetz e suas filhas Cristiane Steinmetz e Adriane Steinmetz, administram a propriedade familiar na produção de soja e milho chamada Fazenda Boa Vista, no município de Mineiros, localizado no estado de Goiás (GO). Diante da pandemia elas criaram em abril de 2020, uma organização denominada por União das Mulheres do Agro (UMA) e um grupo virtual "Mulheres do Agro de Mineiros", contendo um total de 200 participantes que compartilham conhecimentos, constroem narrativas e estratégias, trocam experiências e realizam eventos periodicamente, com intuito de "fortalecer cada vez mais o setor agropecuário feminino para que ele seja reconhecido e respeitado com o devido merecimento", conforme consta no site "Mulheres do Agro" (https://www.mulheresdoagro.com.br/. Acesso em 12/07/2021).

Esses grupos visam disseminar a ideologia de classe do agronegócio via objetivo comum, qual seja, aprofundar a hegemonia do setor capitalista apagando contradições e interesses privados em prol da manutenção de privilégios e desigualdades. Os debates de caráter capitalista e mercadológico realizados nos movimentos organizados pelas mulheres defensoras do agronegócio no país, escamoteiam a violência no campo decorrente do Brasil colônia até os dias atuais, violações contra indígenas, trabalho escravo, desmatamento, uso de agrotóxicos, concentração fundiária, contrarreforma agrária, violência contra os movimentos sociais, entre outras intensas lutas travadas no legado histórico do campo brasileiro diante do desmonte da agricultura camponesa. Uma luta secular "contra a lógica do campo como lugar de negócio, na afirmação da lógica da produção para a sustentação da vida em suas diferentes dimensões, necessidades, formas" (CALDART, 2008, p. 72). 
NASCIMENTO, E. N. S; ALMEIDA, R. A. A mercantilização da educação pública nos moldes...

A educação tem se tornado lócus de atuação desses grupos criados para fortalecer a imagem do agronegócio brasileiro, alcançar admiração e ser consolidado como motor da economia nacional - o Agro é POP. Nesse sentido, o setor agrário utiliza os veículos de comunicação e todos os mecanismos de propaganda por meio da mídia brasileira, para assim manter o campo como setor de investimentos especulativos e de prosperidade privada a fim de superar a crise do capital.

A educação brasileira em sido porta de entrada para o pensamento burguês no sentido de reforçar ideias capitalistas nos bancos escolares. Esse avanço de uma educação com princípios empresariais atuantes no território brasileiro encontra total apoio nas três esferas de poder: federal, estadual e municipal. Na perspectiva de Saviani (1986, p. 35), de fato, “a classe dominante não tem interesse na transformação histórica da escola. Ao contrário, estando ela empenhada na preservação do seu domínio, apenas acionará mecanismos de adaptação que evitem a transformação".

Nesse contexto, demanda-se pelo rompimento histórico do sistema educacional do país, pois, apesar das conquistas ainda percebemos uma profunda distância entre legislações educacionais instituídas pelo Estado e a materialização das políticas públicas, conforme a leitura de Poulantzas (2000). Situação exemplificada na distância entre o discurso de uma educação do campo para todos e a real precariedade dessa oferta escolar.

A lei apenas engana ou encobre, reprime, obrigando a fazer ou proibindo. Também organiza e sanciona direitos reais das classes dominadas (claros que investidos na ideologia dominante e que estão longe de corresponder em sua aplicação à sua forma jurídica) e comporta os compromissos materiais impostos pelas lutas populares às classes dominantes (POULANTZAS, 2000, p. 82).

Poulantzas (1974) em seu engajamento crítico argumenta que o Estado é usado como um instrumento das classes dominantes, para assegurar as 
NASCIMENTO, E. N. S; ALMEIDA, R. A. A mercantilização da educação pública nos moldes...

condições econômicas, políticas e ideológicas em detrimento da acumulação capitalista. Nessa vertente, o Estado enquanto centro do exercício de poder não serve apenas para organizar as classes dominantes, mas também, desarranja as classes dominadas e oprimidas, e emprega a interseção dos setores empresariais no sistema educacional para doutrinar a comunidade escolar por meio de corporações que desenvolvem projetos contraditórios e ofensivos.

Desse modo, o patronato rural se veste com sua ideologia mercadológica e cruza os muros escolares, essa inserção organizada por entidades privadas "retira a possibilidade de existência do caráter público da escola, dado que o ensino promovido neste espaço passa a ser mediado por interesses do mercado" (LAMOSA; LOUREIRO, 2014, p. 533).

\section{CONSIDERAÇÕES FINAIS}

Conclui-se a partir dos fundamentos teóricos e da análise dos programas e organizações "Agrinho, Agronegócio na Escola, Mães do Agro", que se trata de ações que possuem uma pedagogia política e mercadológica voltada a aprimorar a imagem do setor agrário brasileiro, mediante intervenção na educação pública a partir de princípios e interesses do capital. E na conjuntura analisada, em específico o MS, o agronegócio interfere nas instituições escolares, no trabalho do corpo docente e discente, com intuito de promover e consolidar seu ideário de classe.

Historicamente, a escola pública tem sido espaço de disputa, em que os interesses da classe dominante buscam ser hegemônicos. Atualmente, estamos vivenciando uma escola carregada de estratégias e ações empresariais difundidas, principalmente, pela hegemonia do patronato rural, que utiliza o banco escolar como aparelho de valorização e propagação da imagem positiva do agronegócio.

Em razão dos aspectos abordados, foi possível identificar uma diversidade de estratégias da burguesia rentista fortalecidas pelo tripé Estado-Mídia-Capital 
que interferem nas ações pedagógicas das escolas públicas, por meio de materiais, cursos, palestras, formações de professores, incentivos aos alunos, premiações etc. Ideologias empregadas para propagar a lógica privada do sistema capitalista na contramão da educação pública, representadas neste ensaio por três programas/movimentos: programa Agrinho, projeto Agronegócio na Escola, grupo Mães do Agro.

\section{REFERÊNCIAS BIBLIOGRÁFICAS}

ARROYO, Miguel G. Outros sujeitos, outras pedagogias. 2 ed. Petrópolis, RJ: Vozes, 2014.

BOMBARDI, Larissa Mies. Geografia do Uso de Agrotóxicos no Brasil e Conexões com a União Europeia. São Paulo: FFLCH - USP, 2017, 296 p.

CALDART, Roseli Salete. Sobre a Educação do Campo. In: SANTOS, Clarice A. dos. (Orgs.). Por uma Educação do Campo: campo, políticas públicas, educação. Brasília: Incra; MDA, 2008, p.67-86.

. Educação do campo. In: CALDART, R. et al. Dicionário da educação do

campo. RJ/SP: Escola Politécnica de Saúde Joaquim Venâncio, Expressão Popular, 2012.

. Reforma agrária popular e pesquisa. In: ALENTEJANO, P. R. R; CALDART, R. S. (orgs). MST: universidade e pesquisa. São Paulo: Expressão Popular 2014.

CAMACHO, Rodrigo Simão. Paradigmas em Disputa na Educação do Campo. Tese (Doutorado em Geografia) - Faculdade de Ciências e Tecnologia, Universidade Estadual Paulista, Presidente Prudente, 2014.

DUARTE, Newton. Sobre o construtivismo: contribuições a uma análise crítica. Campinas, SP: Autores Associados, 2005. (Coleção do nosso tempo; 77).

IBGE (2006). Censo Agropecuário. Instituto Brasileiro de Geografia e Estatística. Disponível em: http://www.sidra.ibge.gov.br. Acesso em: 27/07/2021.

LAMOSA, Rodrigo de Azevedo Cruz. Estado, Classe Social e Educação no Brasil: uma análise crítica da hegemonia da Associação Brasileira do Agronegócio. $435 f$. Tese (doutorado) - Universidade Federal do Rio de Janeiro, Faculdade de Educação, Programa de Pós-Graduação em Educação, 2014. 
LAMOSA, Rodrigo de Azevedo Cruz; LOUREIRO, Carlos Frederico B. Agronegócio e educação ambiental: uma análise crítica. Revista Ensaio, Rio de Janeiro, v.22, n. 83, p. 533-554, abr./jun. 2014.

LEAL, Hansi Miller Quintino; ALMEIDA, Rosemeire Aparecida de. Agricultura e a sujeição da renda da terra em Mirandópolis/SP. Revista Eletrônica da Associação dos Geógrafos Brasileiros - Seção Três Lagoas Três Lagoas-MS, V 2 - n. ${ }^{\circ}$, setembro de 2005.

MST. Educação do campo: a estratégia dos usurpadores. 2015. Disponível em http://www.mst.org.br/2015/05/20/educacao-no-campo-a-estrategia-dosusurpadores.html. Acesso em 04/06/2021.

PEREIRA, Veninha Bortoluzzi. Programa Agrinho, concepção política- pedagógica para a formação de professores. In: X ANPED SUL, Florianópolis, p. 01-19, outubro de 2014.

Concepção político-pedagógica para formação de professores do Programa Agrinho: do campo à cidade. 136 f. Dissertação (Mestrado em Educação) - Universidade Estadual do Centro-Oeste do Paraná. Guarapuava/PR, 2015.

POULANTZAS, Nicos. Fascism and Dictatorship. London: New Left. 1974.

O Estado, o poder, o socialismo. SP: Paz e Terra, 2000.

ROSSI, Rafael; VARGAS, Icléia Albuquerque de. Ideologia e Educação: Para a Crítica do Programa Agrinho. REVISTA NERA, Presidente Prudente. Nº. 40, Set-Dez, 2017, pp. 206-224. ISSN: 1806-6755.

SAVIANI, Dermeval. Escola e Democracia: teorias da educação, curvatura da vara, onze teses sobre educação e política. 13. ed. Campinas, SP: Cortez Editora/ Autores Associados, 1986. 96 p. (Coleção polêmicas do nosso tempo, v. 5).

- Educação Socialista, Pedagogia Histórico Crítica e os desafios da sociedade de classes. In: LOMBARDI, J.C.; SAVIANI, D. (orgs.) Marxismo e educação/debates contemporâneos. Campinas: Autores Associados: Histedbr, 2008.

Submetido em: 06 de setembro de 2021

Aprovado em: 03 de dezembro de 2021.

Publicado em: 23 de dezembro de 2021. 